\title{
ИЗМЕНЕНИЕ ПОКАЗАТЕЛЕЙ КОСТНОЙ СЛУХОВОЙ ПРОВОДИМОСТИ У СТУДЕНТОВ ПРИ УМСТВЕННОЙ НАГРУЗКЕ НА ОСНОВЕ АУДИОМЕТРИИ
}

\begin{abstract}
CHANGE OF BONE AUDITORY
CONDUCTIVITY IN STUDENTS AT MENTAL
LOAD BASED ON AUDIOMETRY
S. Moryakina
V. Anzorov
Summary. The scientific work presents the dynamics of changes in the bone conductivity of sounds in students of the Biological and Chemical Faculty of the Chechen State University under the influence of the educational load in the comparative aspect on a gender basis. As a result of the studies carried out, it was found that in girls of the second and fifth years sounds of different tonality are better conducted through the bones of the skull. Best of all, second-year students had bone conduction expressed at a high frequency of 3,000 hertz. Fourth year students had sharper hearing, when conducting sounds through skull bones than girls. Students of the fifth year of both sexes heard better at high frequencies - 3000 and 4000 hertz. In all three courses, the bone-air interval was increased at low and medium frequencies $(250,500,750$ hertz) of the right ear. Young men also had the above changes established, but in the fourth and fifth courses they were typical of the left ear, and in the second course they were characteristic of the right ear. Fifth year students also saw an increase in the bone-air interval for the left ear at a high frequency of 4,000 hertz to $15 \mathrm{~dB}$.
\end{abstract}

Keywords: different-sex students, bone conduction, bone-air interval training load.

\section{Ввемение}

$\longrightarrow$

луховая система - вторая по значению в обеспечении адаптивных реакций и познавательной деятельности человека [7].

Исследование воздушной и костной звукопроводимости обычно проводят с использованием аудиометра, который предназначен для оценки функционального состояния слухового анализатора человека путем определения порогов слышимости по воздушному и костному звукопроведению методом сравнения слу-
Морякина Светлана Васильевна

К.б.н., дочент, ФГБОУВО «Чеченский государственный университет» s.moriakina@yandex.ru

Анзоров Ваха Асхадович

Д.б.н., профессор, ФГБОУВО «Чеченский государственный университет» vaha-anzorov@mail.ru

Аннотация. В научной работе представлена динамика изменений костной проводимости звуков у студентов биолого-химическом факультете Чеченского государственного университета при воздействии учебной нагрузки в сравнительном аспекте по гендерному признаку. В результате проведенных исследований было установлено, что у девушек второго и пятого курса звуки различной тональности лучше проводятся через кости черепа. Лучше всего у студентов второго курса костная проводимость была выражена на высокой частоте - 3000 герц. Студенты четвертого курса имели более острый слух, при проведении звуков через кости черепа, чем девушки. Студенты пятого курса обоего пола лучше слышали на высоких частотах 3000 и 4000 герц. У девушек всех трех курсов костно-воздушный интервал был повышен на низких и средних частотах $(250,500,750$ герц) правого уха. у юношей также были установлены вышеизложенные изменения, но у четвертого и пятого курсов они были характерны для левого уха, а у второго курса - для правого. У студентов пятого курса также было отмечено повышение костно-воздушного интервала для левого уха на высокой частоте 4000 герц до 15 дБ.

Ключевые слова: разнополые студенты, костная проводимость, костно-в0здушный интервал учебная нагрузка.

ха, обследуемого с характеристиками, эквивалентными порогу слышимости отологически нормального человека $[6,8]$.

Учебный процесс может оказывать негативное воздействие на функциональную лабильности слуховой системы у студентов и учащейся молодежи.

Поэтому проведенные нами исследования с целью установления изменений остроты слуха при учебной нагрузке у разнополых студентов носят весьма актуальный характер. 
Таблица 1. Характер изменений остроты слуха при костной проводимости у девушек всех курсов

\begin{tabular}{|c|c|c|c|c|c|c|}
\hline \multirow{4}{*}{ Частота в Гц } & \multicolumn{6}{|c|}{ Костная проводимость, дБ } \\
\hline & \multicolumn{6}{|l|}{$M \pm m$} \\
\hline & \multicolumn{2}{|l|}{ Второй курс } & \multicolumn{2}{|l|}{ Четвертый курс } & \multicolumn{2}{|l|}{ Пятый курс } \\
\hline & Левое ухо (AS) & Правое ухо (AD) & Левое ухо (AS) & Правое ухо (AD) & Левое ухо (AS) & Правое ухо (AD) \\
\hline 250 & $5,31 \pm 6,183$ & $5,93 \pm 7,122$ & $5,00 \pm 8,394$ & $7,17 \pm 8,094$ & $8,42 \pm 9,287$ & $7,89 \pm 7,133$ \\
\hline 500 & $9,68 \pm 10,403$ & $7,81 \pm 7,952$ & $8,04 \pm 9,138$ & $6,95 \pm 8,221$ & $7,10 \pm 6,935$ & $7,5 \pm 8,618$ \\
\hline 750 & $6,87 \pm 7,500$ & $4,37 \pm 6,292$ & $7,17 \pm 7,808$ & $7,82 \pm 8,233$ & $8,15 \pm 7,493$ & $3,15 \pm 5,058$ \\
\hline 1000 & $9,37 \pm 7,500$ & $7,81 \pm 6,824$ & $11,30 \pm 10,137$ & $10,65 \pm 9,571$ & $9,21 \pm 9,016$ & $7,10 \pm 7,512$ \\
\hline 1500 & $11,56 \pm 11,65$ & $7,10 \pm 7,719$ & $10,65 \pm 11,412$ & $9,56 \pm 9,643$ & $8,94 \pm 7,742$ & $7,89 \pm 8,219$ \\
\hline 2000 & $7,81 \pm 7,521$ & $8,12 \pm 8,139$ & $8,04 \pm 9,383$ & $8,04 \pm 9,970$ & $3,94 \pm 4,882$ & $6,31 \pm 8,307$ \\
\hline 3000 & $2,50 \pm 4,472$ & $3,12 \pm 6,021$ & $2,39 \pm 3,652$ & $6,30 \pm 7,419$ & $0,52 \pm 2,294$ & $1,57 \pm 4,100$ \\
\hline 4000 & $5,93 \pm 7,576$ & $5,93 \pm 6,884$ & $7,17 \pm 8,233$ & $8,91 \pm 8,655$ & $5,26 \pm 5,13$ & $5,26 \pm 7,35$ \\
\hline
\end{tabular}

Таблица 2. Характер изменений остроты слуха при костной проводимости у юношей всех курсов

\begin{tabular}{|c|c|c|c|c|c|c|}
\hline \multirow{4}{*}{$\begin{array}{l}\text { Частота } \\
\text { в Гц }\end{array}$} & \multicolumn{6}{|c|}{ Костная проводимость, дБ } \\
\hline & \multicolumn{6}{|l|}{$M \pm m$} \\
\hline & \multicolumn{2}{|l|}{ Второй курс } & \multicolumn{2}{|l|}{ Четвертый курс } & \multicolumn{2}{|l|}{ Пятый курс } \\
\hline & Левое ухо (AS) & Правое ухо (AD) & Левое ухо (AS) & Правое ухо (AD) & Левое ухо (AS) & Правое ухо (AD) \\
\hline 250 & $13,33 \pm 15,275$ & $6,66 \pm 11,547$ & $2,85 \pm 7,559$ & $4,28 \pm 7,868^{*}$ & $13,33 \pm 5,774$ & $11,66 \pm 5,774$ \\
\hline 500 & $13,33 \pm 18,93$ & $20,0 \pm 18,028$ & $0,71 \pm 1,89$ & $2,85 \pm 7,559^{*}$ & $8,33 \pm 5,774$ & $8,33 \pm 2,887$ \\
\hline 750 & $8,33 \pm 10,48$ & $11,66 \pm 7,638$ & $0,0 \pm 0,0$ & $2,85 \pm 4,88$ & $8,33 \pm 10,408$ & $8,33 \pm 10,408$ \\
\hline 1000 & $20,0 \pm 20,0$ & $15,00 \pm 8,660$ & $4,28 \pm 7,868$ & $5,00 \pm 9,574$ & $18,33 \pm 2,887$ & $16,66 \pm 10,408$ \\
\hline 1500 & $16,66 \pm 15,275$ & $15,00 \pm 8,660$ & $1,42 \pm 3,78^{* * *}$ & $4,28 \pm 7,868$ & $11,66 \pm 2,887$ & $8,33 \pm 10,408$ \\
\hline 2000 & $5,00 \pm 5,000$ & $10,00 \pm 5,0$ & $0,0 \pm 0,0$ & $3,57 \pm 7,480$ & $11,66 \pm 20,207$ & $3,33 \pm 5,774$ \\
\hline 3000 & $3,33 \pm 2,887$ & $5,0 \pm 8,66$ & $0,0 \pm 0,0$ & $0,71 \pm 1,89$ & $0,0 \pm 0,0^{* * * *}$ & $0,0 \pm 0,0$ \\
\hline 4000 & $11,66 \pm 12,583$ & $13,33 \pm 12,583$ & $0,71 \pm 1,89^{* *}$ & $2,14 \pm 5,66^{*}$ & $1,66 \pm 2,8982$ & $0,0 \pm 0,0$ \\
\hline
\end{tabular}

Примечание: *P $<0,05 ;{ }^{* * P}<0,02 ;{ }^{* *} \mathrm{P}<0,01 ;{ }^{* * *} \mathrm{P}<0,001$

Цель настоящей работы состояла в изучении функционального состояния слуховой системы у студентов разного пола при костной проводимости звуковых сигналов.

Для выполнения поставленной цели решались следующие задачи:

1. Изучение слуховой чувствительности при костной проводимости звуков у девушек и юношей 2-х, 4-х и 5-х курсов.

2. Сопоставление остроты слуха при костной проводимости для правого и левого уха отдельно у девушек и юношей всех курсов.

3. Определение наличия кондуктивного компонента (костно-воздушного интервала) на каждой из исследуемых частот.

\section{Материал и методы исследования}

Всего было обследовано 72 студента (57 девушек и 15 юношей) 2-го, 4-го, и 5-го курсов, которые составили три группы, каждая из которых была разделена по признаку пола две подгруппы. Экспериментальный материал был собран в лаборатории «Физиология человека» с октября по декабрь 2019 года.

Для костной проводимости звука использовались следующие частоты: 250, 500, 750, 1000, 1500, 2000, 3000, 4000 Гц.

Изучение костной проводимости звуков проводили с помощью автоматизированного аудиометра АА-02. Тест проводился от 10 до 15 минут [9]. 


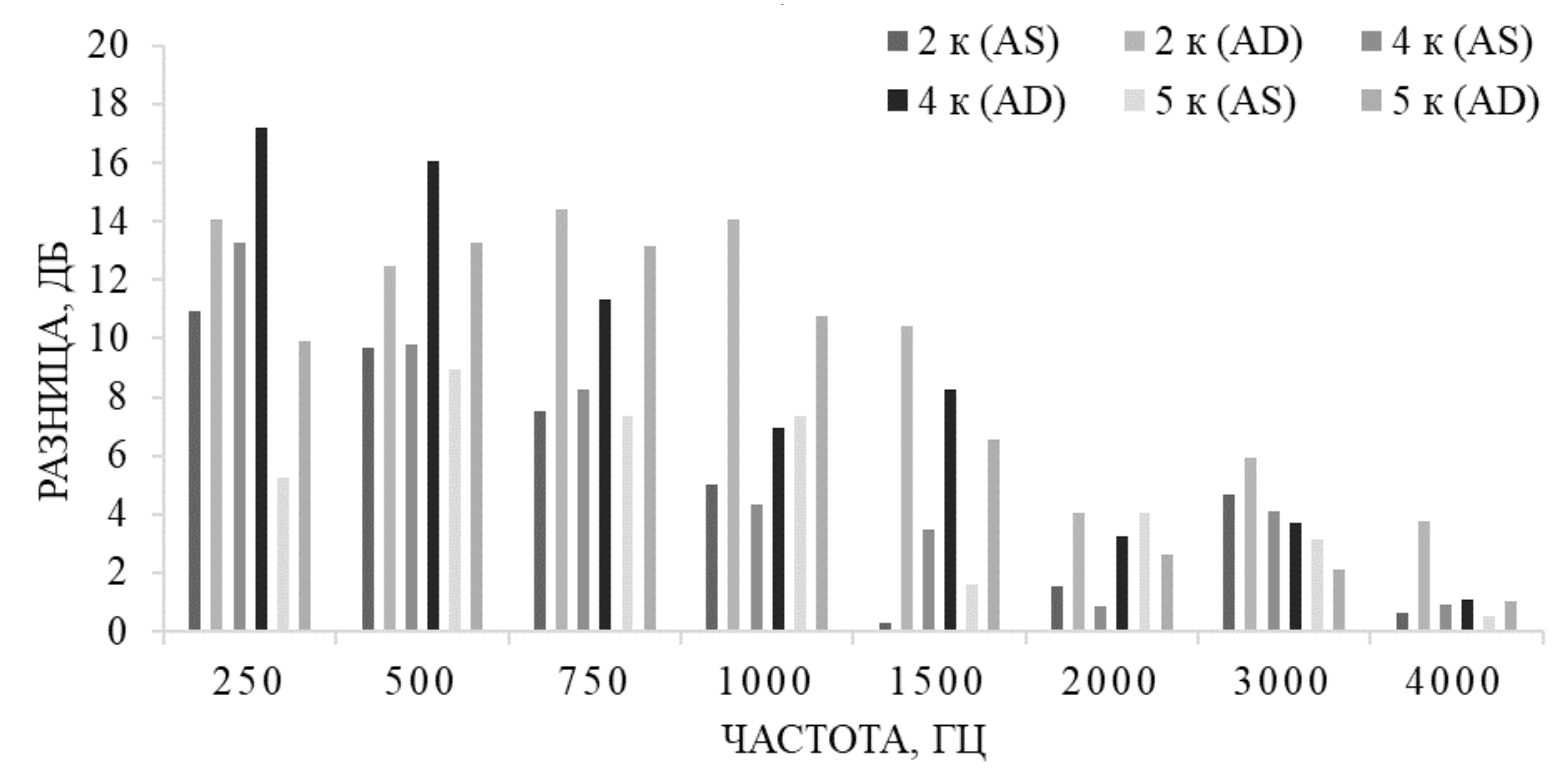

Рис. 1. Разность между значениями порогов слышимости, определенными при воздушном и костном звукопроведении у девушек всех курсов

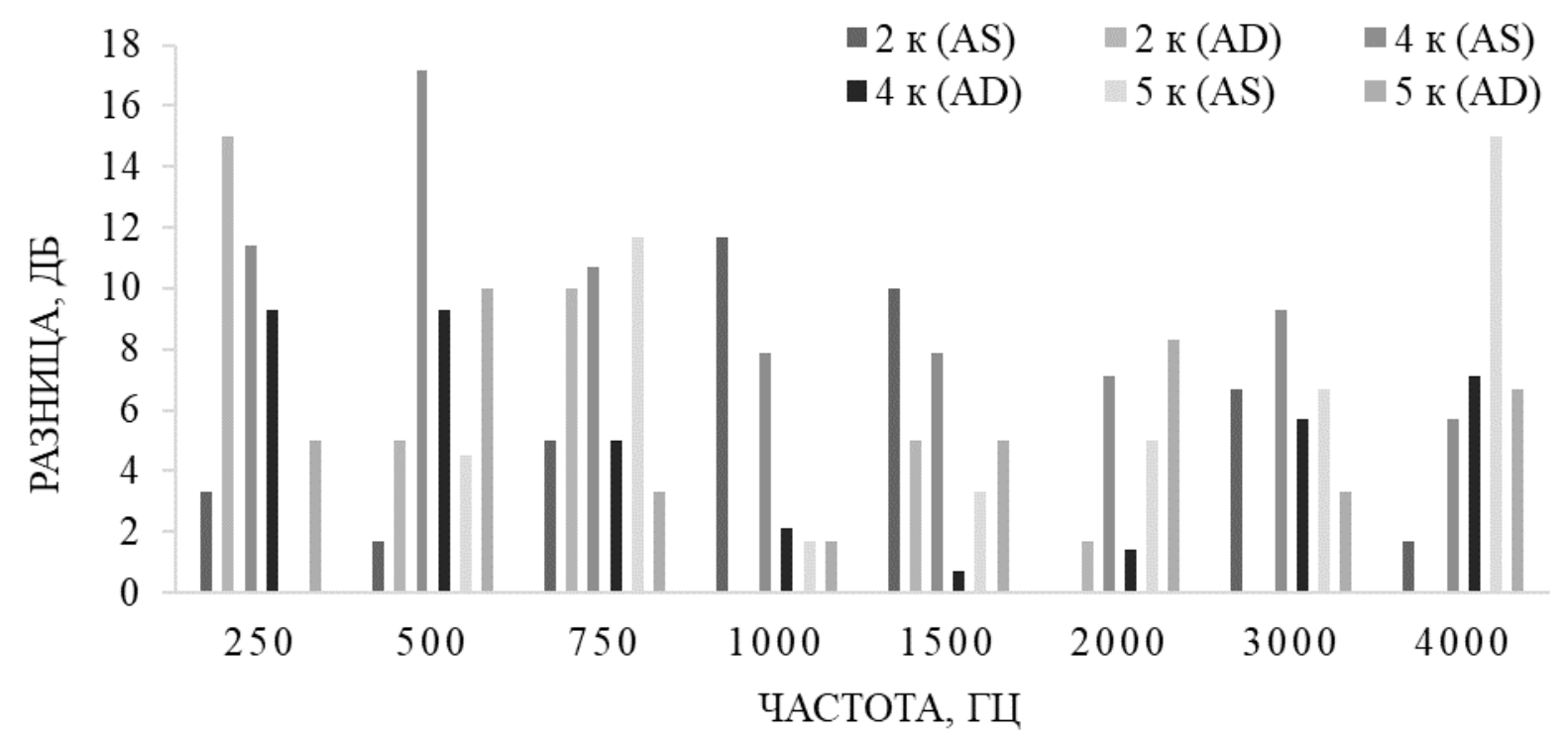

Рис. 2. Разность между значениями порогов слышимости, определенными при воздушном и костном звукопроведении у юношей всех курсов

Для статистической обработки использовалась программа «Excel 2016».

\section{Результаты исслеАований \\ и обсу жАение}

Из таблицы 1 и 2 следует, что костная проводимость звуков наиболее выражена для обоих ушей у девушек и юношей 2-го курса, практически на всех изучаемых частотах. Лучше всего студенты слышали на высокой частоте - 3000 герц.

Проанализировав результаты исследований студентов обоего пола четвертого курса, мы пришли к заключению, что наименьшая величина слуховой чувствительности для костной проводимости характерна в полной мере для левого уха у юношей и по большинству частот у девушек. 
Студенты четвертого курса имели более острый слух, при проведении звуков через кости черепа, чем девушки.

Девушки и юноши пятого курса отличились более высокой костной проводимостью для правого уха. Кроме того, у девушек, в сопоставлении с юношами звуки, поступающие через кости черепа, воспринимались рецепторами внутреннего уха значительно лучше, чем у юношей.

Мы также произвели сопоставление остроты слуха при костной проводимости для правого и левого уха отдельно у девушек и юношей всех курсов.

Наиболее высокие пороги слуховой чувствительности и соответственно, более низкая острота слуха, были отмечены у девушек второго курса, для средних частот 1000 герц, у юношей - 250, 500, 10001500 и 4000 герц.

Хуже всего студентками четвертого курса воспринимались средние частоты - 1000 и 1500 герц. У студентов четвертого курса нарушений слуха мы не обнаружили

Студенты пятого курса показали наихудшие результаты на частотах: 250, 1000, 1500 и 2000 герц (низкая острота слуха), особенно для левого уха. У девушек нарушений мы не обнаружили (табл. 1,2).

Мы также произвели сопоставление остроты слуха при костной проводимости для правого и левого уха отдельно у девушек и юношей всех курсов.

Наиболее высокие пороги слуховой чувствительности и соответственно, более низкая острота слуха, были отмечены у девушек второго курса, для средних частот 1000 герц, у юношей — 250, 500, 10001500 и 4000 герц.

Хуже всего студентками четвертого курса воспринимались средние частоты - 1000 и 1500 герц. У студентов четвертого курса нарушений слуха мы не обнаружили

Студенты пятого курса показали наихудшие результаты на частотах: 250, 1000, 1500 и 2000 герц (низкая острота слуха), особенно для левого уха. У девушек нарушений мы не обнаружили (табл. 1,2).

Разность между значениями порогов слышимости, определенными при воздушном и костном звукопроведении, которая отражается на аудиограмме в виде костно-воздушного интервала показала следующие результаты.

Нами было установлено, что у девушек всех трех курсов костно-воздушный интервал был повышен на низ- ких и средних частотах (250, 500, 750 герц) правого уха (особенно у девушек четвертого курса). У юношей также были установлены вышеизложенные изменения, но у четвертого и пятого курсов они были характерны для левого уха, а у второго курса - для правого. Возможно, в данном случае, имеет место перенесенное воспаление среднего уха (отит), которое привело к нарушению звукопроводящей системы слуха (кондуктивные нарушения) [10].

В нашем случае пока не идет речь о кондуктивной тугоухости, так как разница между значениями порогов слышимости, определенными при воздушном и костном звукопроведении, не превышает 17,2 дБ (рис. 1,2). А из литературных источников нам известно, что в случае патологии среднего уха пороги повышаются на низких частотах на 20-40 дБ [2].

У студентов пятого курса также было отмечено повышение костно-воздушного интервала для левого уха на высокой частоте 4000 герц до 15 дБ.

В данном случае имеют место нейросенсорные нарушения при поражении звуковоспринимающего аппарата. Причиной может быть воздействие постоянного шума на орган слуха. Возможно, эти студенты злоупотребляют громкой музыкой, особенно через наушники плееров, или постоянно «висят» на телефоне [1].

\section{Зак^ючение}

После проведенных исследований по костной проводимости можно сделать заключение, что у девушек второго и пятого курса звуки различной тональности, выраженной в герцах, лучше проводятся через кости черепа. Возможно, это связано с тем, что у девушек более тонкие кости черепа и поэтому звуковой сигнал быстрее доходит до фонорецепторов внутреннего уха.

Лучше всего студенты второго курса слышали на высокой частоте - 3000 герц. Студенты четвертого курса имели более острый слух, при проведении звуков через кости черепа, чем девушки. Студенты пятого курса обоего пола лучше слышали на высоких частотах - 3000 и 4000 герц.

Большинство студентов на низких и средних частотах 250, 1000, 1500 и 2000 герц показали самый высокий порог слышимости (низкая острота слуха), особенно для левого уха. Причиной может быть слишком активное использование мобильных телефонов, которые обычно прикладывают к левому уху. Это создает шумовую нагрузку. Причиной также может быть слишком частое прослушивание музыки через наушники $[3,4,5]$. 


\section{ЛИТЕРАТУРА}

1. Авдеева Е.В., Снегирева Л. В. Изучение воздействия мобильных устройств на остроту слуха // Актуальные вопросы модернизации российского образования: Материалы Международного электронного Симпозиума, 11 мая 2015 г. Махачкала, 2015. С. 5-10.

2. Баданов А. В. Влияние учебной нагрузки на умственное и физическое состояние студентов // Вестник Бурятского государственного университета. Улан-Удэ: Бурятский государственный университет, 2011. № 13. С. 12-15.

3. Беленко Н.Ю., Калинина Т. Е. 0 распределении первичных ответов на звуковое раздражение в коре больших полушарий // Журнал высшей нервной деятельности им. И. П. Павлова. 1973. Т. 15. С. 67-69.

4. Берест А.Ю., Красненко А. С. Влияние Регулярного использования аудиоплееров с наушниками на слуховую функцию лиц молодого возраста // Российская оториноларингология. 2013. № 1 (62). С. 32-35.

5. Богомольский М. Р. Воздействие звуковых сигналов высокой интенсивности на слуховой анализатор // Вестник оториноларингологии. 2006. № 3. С. 31-33.

6. Изергина К. С. Аудиометрическое обследование // Сборник статей ХІ Международной научно-практической конференции «Современная наука: актуальные вопросы, достижения и инновации». 05 февраля 2020 г. Издательство: «Наука и Просвещение». Пенза, 2020. С. $205-207$.

7. Каюмова А.В. и др. Физиология сенсорных систем: учебно-методическое пособие. Изд-во ГОУ ВПО «БГмУ Росздрава», 2011. 115 с.

8. Найда С. А. Объективная аудиометрия слуха человека // Електроніка та звязок. 2012. № 4 (69). С. 33-37.

9. Таварткиладзе Г.А., Гвелесиани Т. Г. Клиническая аудиология. М.: Святигор Пресс, 2003. 74 с.

10. Терютин Ф.М., Барашков Н. А., Федотова Э. Е. Аудиологический анализ состояния слуха в случайной выборке лиц молодого возраста. Российская оториноларингология. 2012. № 4 (59). С. 101-110.

( ) Морякина Светлана Васильевна ( s.moriakina@yandex.ru ),Анзоров Ваха Асхадович (vaha-anzorov@mail.ru).

Журнал «Современная наука: актуальные проблемы теории и практики»

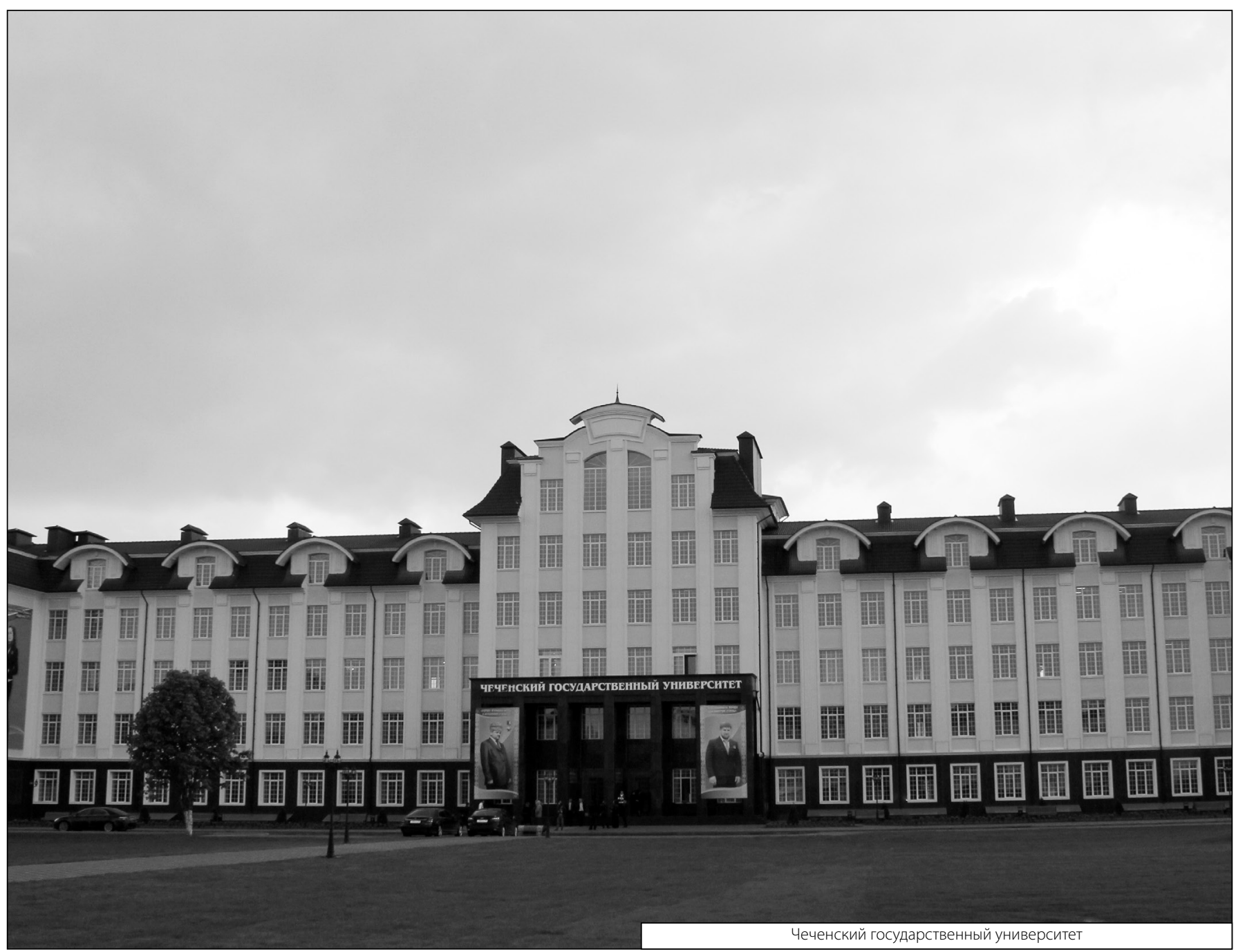

